\title{
PROGRAMA DE CIENCIAS NATURALES
}

En la última década, la enseñanza de las Ciencias Naturales ha experimentado un cambio fundamental. El énfasis en los contenidos y su memorización, característica de la enseñanza tradicional, ha quedado atrás, dando paso a la necesidad de formar en el alumno conductas científicas que lo lleve a encontrar por sí mismo nuevas leyes y principios.

Para responder a esta inquietud, el grupo de Ciencias del Centro de Investigaciones de la Universidad Pedagógica Nacional, continuando la tarea iniciada en el antiguo Icolpe, diseñó y elaboró un currículo para el primer año de primaria a partir de la sistematización de procesos, propuesta por la Sociedad Americana para el Avance de las Ciencias.

Uno de los intereses que motivó esta programación fue tratar de remediar, en parte, la carencia de programas a nivel de pre-escolar en las escuelas.

Si bien es cierto que se habla de un currículo para el primer año, se busca fundamentalmente iniciar al niño en el aprendizaje de las ciencias ya sea en primero o pre-escolar y establecer precurrencias para el aprendizaje de otras áreas como Matemáticas y Lenguaje.

Su objetivo es iniciar al niño en la formación científica, a través del desarrollo de conductas científicas sistematizadas. Esto implica que el alumno aprenderá ciencias, haciendo ciencia a su nivel, es decir, viviendo los procesos que constituyen el quehacer científico: Observar, clasificar, medir, comunicar, emplear relaciones espacio temporales, inferir, predecir, interpretar datos, controlar variables, definir operacionalmente, formular hipótesis, experimentar, etc.

Para el primer curso, se introducen los procesos de observación, clasificación, medición, relaciones espacio-temporales en sus niveles más elementales.

Se busca fundamentalmente dar oportunidad al niño de experimentar, expresar, valorar y verificar sus ideas: en una palabra formar actitudes creadoras y críticas.

El programa está estructurado en tres unidades, cada una de las cuales presenta un objetivo general, desglosado en objetivos específicos, que presentan las correspondientes situaciones de aprendizaje y los recursos necesarios. Cada grupo de objetivos específicos hace referencia a los procesos en su correspondiente nivel, y al final presenta una evaluación para determinar el dominio de aprendizaje logrado por cada niño.

Cabe destacar que el programa fue objeto de una evaluación formativa que se cumplió en el Instituto Pedagógico Nacional de Bogotá, durante el año de 1976.

El trabajo será publicado próximamente como material de apoyo para el proyecto de Escuela Nueva. 